\title{
Crocetin induces cytotoxicity and enhances vincristine-induced cancer cell death via p53- dependent and -independent mechanisms
}

\author{
Ying-jia ZHONG ${ }^{1,2}$, Fang $S H{ }^{1}$, Xue-lian ZHENG ${ }^{1}$, Qiong WANG ${ }^{1}$, Lan YANG ${ }^{1}, H_{\text {Hong SUN }}^{1}$, Fan HE ${ }^{1}$, Lin ZHANG ${ }^{1}$, Yong LIN $^{1}$, \\ Yong $\mathrm{QIN}^{3}$, Lin-chuan $\mathrm{LIAO}^{2, *}$, Xia WANG ${ }^{1, *}$ \\ ${ }^{1}$ Laboratory of Molecular and Translational Medicine, Key Laboratory of Obstetric, Gynecologic and Pediatric Diseases and Birth \\ Defects of the Ministry of Education, West China Second University Hospital, Sichuan University, Chengdu 610041, China; ${ }^{2}$ Depart- \\ ment of Forensic Analytical Toxicology, West China School of Preclinical and Forensic Medicine, Sichuan University, Chengdu 610041, \\ China; ${ }^{3}$ Department of Chemistry of Medicinal Natural Products, Key Laboratory of Drug Targeting and Novel Delivery System of the \\ Ministry of Education, West China School of Pharmacy, Sichuan University, Chengdu 610041, China
}

\begin{abstract}
Aim: To investigate the anticancer effect of crocetin, a major ingredient in saffron, and its underlying mechanisms.
Methods: Cervical cancer cell line HeLa, non-small cell lung cancer cell line A549 and ovarian cancer cell line SKOV3 were treated with crocetin alone or in combination with vincristine. Cell proliferation was examined using MTT assay. Cell cycle distribution and sub- $\mathrm{G}_{1}$ fraction were analyzed using flow cytometric analysis after propidium iodide staining. Apoptosis was detected using the Annexin V-FITC Apoptosis Detection Kit with flow cytometry. Cell death was measured based on the release of lactate dehydrogenase (LDH). The expression levels of $\mathrm{p} 53$ and $\mathrm{p} 21^{\mathrm{WAF} 1 / \mathrm{Cip} 1}$ as well as caspase activation were examined using Western blot analysis.

Results: Treatment of the 3 types of cancer cells with crocetin (60-240 $\mu \mathrm{mol} / \mathrm{L})$ for $48 \mathrm{~h}$ significantly inhibited their proliferation in a concentration-dependent manner. Crocetin $(240 \mu \mathrm{mol} / \mathrm{L})$ significantly induced cell cycle arrest through p53-dependent and -independent mechanisms accompanied with p $21^{\text {WAF } 1 / \text { Cip } 1}$ induction. Crocetin $(120-240 \mu \mathrm{mol} / \mathrm{L})$ caused cytotoxicity in the 3 types of cancer cells by enhancing apoptosis in a time-dependent manner. In the 3 types of cancer cells, crocetin ( $60 \mu \mathrm{mol} / \mathrm{L})$ significantly enhanced the cytotoxicity induced by vincristine $(1 \mu \mathrm{mol} / \mathrm{L})$. Furthermore, this synergistic effect was also detected in the vincristine-resistant breast cancer cell line MCF-7/VCR.

Conclusion: Ccrocetin is a potential anticancer agent, which may be used as a chemotherapeutic drug or as a chemosensitizer for vincristine.
\end{abstract}

Keywords: crocetin; vincristine; cell cycle; apoptosis; p53; neoplasm

Acta Pharmacologica Sinica (2011) 32: 1529-1536; doi: 10.1038/aps.2011.109; published online 10 Oct 2011

\section{Introduction}

Saffron, which is the flower of Crocus sativus L, is an important dietary ingredient in India and other tropical countries. In addition to its use as a spice and a food colorant, saffron is administered as an analgesic and cardioprotective agent, as well as in treatment of various mental illnesses in traditional Indian medicine. Crocetin (8, 8'-diapo-8, 8'-carotenoic acid), which is the major ingredient of saffron that is responsible for its coloring property, is a low-molecular-weight carotenoid

\footnotetext{
* To whom correspondence should be addressed.

E-mail xiawang@scu.edu.cn (Xia WANG); linchuanliao@scu.edu.cn (Lin-chuan LIAO)

Received 2011-02-16 Accepted 2011-07-13
}

compound characterized by a diterpenic and symmetrical structure with seven double bonds and four methyl groups. This compound exhibits antioxidant ${ }^{[1,2]}$, antihyperlipidemic ${ }^{[3]}$, antiatherosclerotic ${ }^{[4,5]}$, cardioprotective ${ }^{[6]}$, hepatoprotective ${ }^{[7]}$, and neuroprotective effects ${ }^{[8]}$ in vitro and in vivo. Therefore, crocetin exhibits favorable effects in the prevention or treatment of a variety of diseases such as dyslipidemia, atherosclerosis, myocardial ischemia, hemorrhagic shock and arthritis ${ }^{[9]}$.

In recent years, considerable effort has been made to identify new chemotherapeutic or chemopreventive agents for cancer. Naturally occurring compounds in food or medicinal plants are ideal candidates for new anticancer agents because they are generally safe and are associated with low toxicity. Crocetin causes cell growth inhibition or induces cell death in several 
malignant cells including human rhabdomyosarcoma (RD) cells ${ }^{[10]}$, pancreatic cancer cells ${ }^{[11]}$, and breast cancer cells ${ }^{[12]}$ in in vitro studies. In the pancreatic cancer xenograft mouse model, significant regression in tumor growth with inhibition of proliferation and enhanced apoptosis was observed in crocetin-treated animals compared with the control animals ${ }^{[11]}$. In addition, crocetin inhibits 12-O-tetradecanoylphorbol-13acetate (TPA)-induced skin tumors in the tobacco-specific carcinogen benzo(a)pyrene $[\mathrm{B}(\mathrm{a}) \mathrm{P}]$ initiated mice ${ }^{[13]}$ and exhibits protective effects against $\mathrm{B}(\mathrm{a}) \mathrm{P}$-induced lung carcinogenesis ${ }^{[14]}$. Collectively, these studies provide evidence of the antitumor activity of crocetin.

Saffron is expensive and has limited availability. To avoid high costs of saffron, Prof Yong QIN's laboratory (Sichuan University, China) has successfully synthesized crocetin using total synthesis. Given the importance of crocetin as a potential anticancer agent, the present study was designed to examine the effect of crocetin on several types of human cancer cells. Crocetin inhibited cell proliferation by inducing cell cycle arrest in cancer cells that were derived from the cervix (HeLa), ovary (SKOV3), and lung (A549) through p53-dependent and -independent mechanisms. Crocetin induced cytotoxicity in these cancer cells by enhancing apoptosis in a time-dependent manner. In the present study, we demonstrated that crocetin significantly sensitized these cancer cells to vincristineinduced cell death and that the synergistic effect was detected in a vincristine-resistant breast cancer cell line. Altogether, this study suggests that crocetin is a potential chemopreventive agent and a potential anticancer agent that can be used as a chemotherapeutic drug or a chemosensitizer for vincristine.

\section{Materials and methods Reagents}

Crocetin was kindly provided by Prof Yong QIN's laboratory (Sichuan University, Chengdu, China). Vincristine (VCR), propidium iodide (PI), and MTT (3-(4,5-dimethylthiazolyl-2)2,5-diphenyltetrazolium bromide) were purchased from Sigma (St Louis, MO, USA). The pan-caspase inhibitor Z-VAD-FMK was purchased from Calbiochem (La Jolla, CA, USA). Antibodies against active caspase-3, poly(ADP-ribose) polymerase (PARP) were purchased from BD Biosciences (San Diego, CA, USA). Anti-caspase-9 and anti-p53 were purchased from Cell Signaling (Beverly, MA, USA). Anti- $\beta$-actin was purchased from Proteintech (Chicago, IL, USA). Anti-p21 ${ }^{\mathrm{WAF} / \mathrm{Cip} 1}$ was purchased from Santa Cruz Biotechnology (Santa Cruz, CA, USA).

\section{Cell culture}

The cervical cancer cell line HeLa, non-small cell lung cancer cell line A549, and ovarian cancer cell line SKOV3 were purchased from the American Type Culture Collection (ATCC, Manassas, VA, USA). These cells were grown in RPMI-1640 or DMEM supplemented with $10 \%$ fetal bovine serum (FBS), $1 \mathrm{mmol} / \mathrm{L}$ glutamate, 100 units/mL penicillin, and $100 \mu \mathrm{g} /$ $\mathrm{mL}$ streptomycin and cultured in an incubator $\left(37^{\circ} \mathrm{C}, 5 \% \mathrm{CO}_{2}\right)$.
The vincristine-resistant mammary cancer cell line MCF-7/ VCR was obtained from the Immunology Department at the West China School of Preclinical and Forensic Medicine at Sichuan University. MCF-7/VCR cells are cross-resistant to doxorubicin and were grown in RPMI-1640 containing 10\% FBS and $1 \mu \mathrm{mol} / \mathrm{L}$ vincristine under standard conditions. The cells were cultured in the absence of vincristine one week before performing experiments.

\section{MTT assay}

Cell proliferation was measured by MTT assays as previously described $^{[15]}$. Briefly, cells were treated with different doses of crocetin for $48 \mathrm{~h}$. Treated cells were incubated with MTT for approximately $3 \mathrm{~h}$, rinsed two times with phosphate buffered saline (PBS), and dissolved with DMSO. The absorbance of the samples was measured at $570 \mathrm{~nm}$ using a plate reader. All the experiments were repeated three times, and the averaged result is shown in each figure.

\section{Flow cytometric analysis}

Flow cytometry was used to analyze the cell cycle distribution. After being treated as indicated in each figure legend, the cells were trypsinized, washed once with PBS, and fixed in $70 \%$ ethanol on ice for $1 \mathrm{~h}$. Fixed cells were resuspended in PBS containing RNase $(100 \mu \mathrm{g} / \mathrm{mL})$ at $37{ }^{\circ} \mathrm{C}$ for $30 \mathrm{~min}$. After digestion of cellular RNA, the cells were stained with propidium iodide (PI) staining solution $(0.2 \% \mathrm{FBS}$ and $25 \mu \mathrm{g} / \mathrm{mL}$ PI in PBS) at room temperature for $1 \mathrm{~h}$ in the dark. The stained cells were analyzed using a FAScan flow cytometer (Beckman Coulter Cell). To assess apoptosis, HeLa cells were treated with crocetin as indicated in each figure legend and double stained with Annexin V-FITC and PI using the Annexin V-FITC Apoptosis Detection Kit (Nanjing KeyGen Biotech, Nanjing, China) followed by flow cytometric analysis. Early apoptosis was defined by Annexin $\mathrm{V}^{+} / \mathrm{PI}^{-}$staining (Q4), and late apoptosis was defined by Annexin $\mathrm{V}^{+} / \mathrm{PI}^{+}$staining $(\mathrm{Q} 2)$.

\section{Cell death assay}

After each designated treatment, cell death was detected based on the release of lactate dehydrogenase (LDH) using a cytotoxicity detection kit (Promega, Madison, WI, USA) as previously described $^{[16]}$. All of the experiments were repeated three to five times, and the averaged result is shown in each figure.

\section{Western blot analysis}

Cell lysate was collected by lysing cells in M2 lysis buffer $[20 \mathrm{mmol} / \mathrm{L}$ Tris- $\mathrm{HCl}$ ( $\mathrm{pH} 7.6), 0.5 \% \mathrm{NP} 40,250 \mathrm{mmol} /$ $\mathrm{L} \mathrm{NaCl}, 3 \mathrm{mmol} / \mathrm{L}$ EDTA, $3 \mathrm{mmol} / \mathrm{L}$ EGTA, $2 \mathrm{mmol} / \mathrm{L}$ DTT, $0.5 \mathrm{mmol} / \mathrm{L}$ phenylmethylsulfonyl fluoride, $20 \mathrm{mmol} /$ $\mathrm{L} \beta$-glycerophosphate, $1 \mathrm{mmol} / \mathrm{L}$ sodium vanadate, and 1 $\mu \mathrm{g} / \mathrm{mL}$ leupeptin]. Cell extracts were subjected to SDS-PAGE and analyzed by Western blot. The proteins were visualized by enhanced chemiluminescence (Millipore, Billerica, MA, USA) using the BIO-RAD Image station. Each experiment was repeated at least three times, and representative results are shown. 


\section{Statistical analysis}

The data were represented as the mean \pm standard deviation (SD) from at least three independent experiments. The 95\% confidence limits of the $\mathrm{IC}_{50}$ values were calculated. Comparisons between groups were performed by paired Student's $t$ test using the SPSS statistics software package (IBM SPSS, Chicago, IL, USA). $P<0.05$ was used for statistical significance.

\section{Results}

\section{Crocetin inhibits cell proliferation in cancer cells}

Crocetin inhibits cell proliferation in pancreatic adenocarcinoma cells and breast cancer cells ${ }^{[11,12]}$. We first tested the effect of crocetin on several cancer cell types to determine whether the antiproliferative effect was common in different cancer cell types. We first treated cervical cancer HeLa cells with different doses of crocetin for $48 \mathrm{~h}$. The MTT assay was used to measure viable cells. As shown in Figure 1A, crocetin reduced viable cell numbers in a dose-dependent manner, showing a pronounced effect at the higher concentration, ie, with a reduction of viability of approximately $80 \%$ at a concentration of $240 \mu \mathrm{mol} / \mathrm{L}$ crocetin. Under these experimental conditions, marginal cell death was observed. The reduction of viable cell numbers detected by the MTT assay was mainly attributed to inhibition of cell proliferation. Similar dosedependent anti-proliferation effects of crocetin were observed in non-small cell lung cancer A549 cells and ovarian cancer SKOV3 cells (Figure $1 \mathrm{~B}$ and $1 \mathrm{C}$ ). The $\mathrm{IC}_{50}$ values and $95 \%$ confidence limits of crocetin for HeLa, A549, and SKOV3 cells were $119.32 \mu \mathrm{mol} / \mathrm{L}(104.24-134.83 \mu \mathrm{mol} / \mathrm{L}), 101.34 \mu \mathrm{mol} / \mathrm{L}$ (88.07-117.65 $\mathrm{mol} / \mathrm{L})$, and $119.76 \mu \mathrm{mol} / \mathrm{L}$ (97.14-143.40 $\mu \mathrm{mol} / \mathrm{L})$, respectively. Therefore, these results suggest that crocetin effectively suppresses proliferation in the tested cancer cells.

\section{Crocetin inhibits cancer cell proliferation by inducing cell cycle arrest at the $\mathrm{G}_{1}$ checkpoint}

To investigate the underlying mechanism for crocetin-induced proliferation inhibition, we examined the cell cycle distribution in crocetin-treated cancer cells using flow cytometric analysis based on cellular DNA content. Crocetin significantly increased the number of HeLa cells in the $G_{1}$ phase, which was detected at $8 \mathrm{~h}$ post crocetin treatment (Figure 2, upper panel). Crocetin-induced $\mathrm{G}_{1}$ phase distribution was time-dependent, and the percentages of cells in the $G_{1}$ phase increased from $33 \%$ in untreated HeLa cells to $41 \%$ in HeLa cells after $24 \mathrm{~h}$ of crocetin treatment. At the same time, the populations of cells in the $S$ or $G_{2}$ phases were markedly reduced. Consistent with its effect on HeLa cells, crocetin showed similar effects on the cell cycle of A549 and SKOV3 cells (Figure 2, middle and lower panels). These results indicate that crocetin inhibits cell proliferation by inducing $\mathrm{G}_{1}$ arrest in cancer cells.

\section{Crocetin induces cell cycle arrest through p53-dependent and -independent mechanisms}

p53 regulates the $G_{1}$ checkpoint by activating transcription of genes that influence cell-cycle progression, including cyclindependent kinase inhibitor p21 $1^{\mathrm{WAF} 1 / \mathrm{Cip} 1}$ and GADD45 ${ }^{[17]}$. To explore the role of p53 and its downstream genes in crocetininduced cell cycle regulation, we detected the expression levels of $\mathrm{p} 53$ and $\mathrm{p} 21^{\mathrm{WAF} 1 / \mathrm{Cip} 1}$ in crocetin treated cells. As shown in Figure $3 \mathrm{~A}$, crocetin induced p53 and p21 ${ }^{\text {WAF1/Cip1 }}$ accumulation in A549 cells, which have functional wild-type p53. Furthermore, crocetin induced the increase of p53 and p $21^{\text {WAF1/Cip1 }}$ in HeLa cells, which express low basal levels of p53 because p53 is degraded via interactions with the E6 gene product of HPV (Figure 3B). Therefore, crocetin may cause $\mathrm{G}_{1}$ arrest through p53 and its downstream p $21^{\text {WAF1/Cip1 }}$. Importantly, the p53-independent pathway may also be involved in cell cycle regulation by crocetin, because crocetin also caused $\mathrm{G}_{1}$ arrest in SKOV3 cells that have lost p53 expression and function due to a mutation in the p53 gene (Figure 2, lower panel). Crocetin substantially induced p $21^{\text {WAF1/Cip1 }}$ in SKOV3 cells (Figure $3 C)$. These results indicate that a p53-independent mechanism is involved in upregulation of $\mathrm{p} 21^{\mathrm{WAF} 1 / \mathrm{Cip} 1}$, which induces $\mathrm{G}_{1}$ arrest. Altogether, these results suggest that crocetin regulates cancer cell proliferation through p53-dependent and -independent induction of $\mathrm{p} 21^{\text {WAF1/Cip1 }}$.

\section{Crocetin induces cell death by enhancing apoptosis in cancer cells}

We further investigated whether crocetin caused cell death in HeLa, A549, and SKOV3 cells after extending the incubation time of drug with the cells. Although marginal cell death was induced by crocetin at early times, significant cell death was detected by the LDH release assay in HeLa cells after crocetin treatment for $72 \mathrm{~h}$ (Figure 4A). As shown in Figure 4B, $4 \mathrm{C}$, and $4 \mathrm{D}$, crocetin induced significant cell death in a dosedependent manner by approximately $40 \%-50 \%$ in all cell lines after treatment with the highest concentration of crocetin. To determine the type of cell death induced by crocetin, HeLa
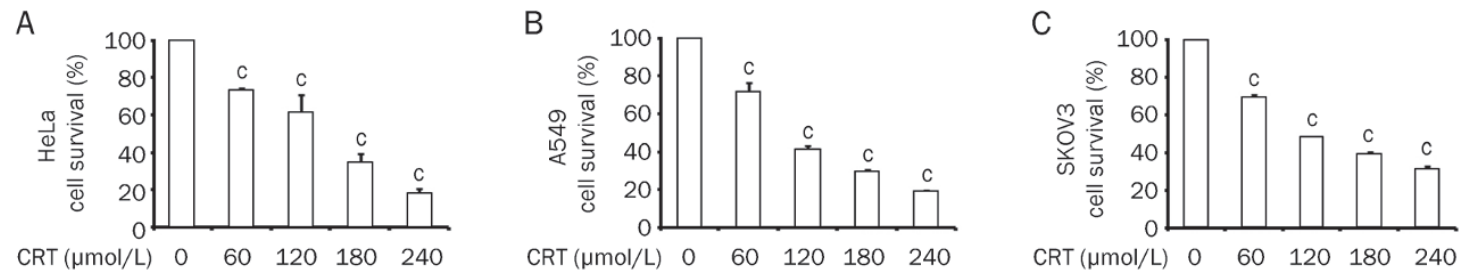

Figure 1. Crocetin (CRT) inhibits cell proliferation in cancer cells. HeLa (A), A549 (B), and SKOV3 cells (C) were treated with different concentrations of crocetin for $48 \mathrm{~h}$. Cell survival was quantitated using MTT assays. $n=3$. Mean \pm SD. ${ }^{\circ} P<0.01$ vs control. 

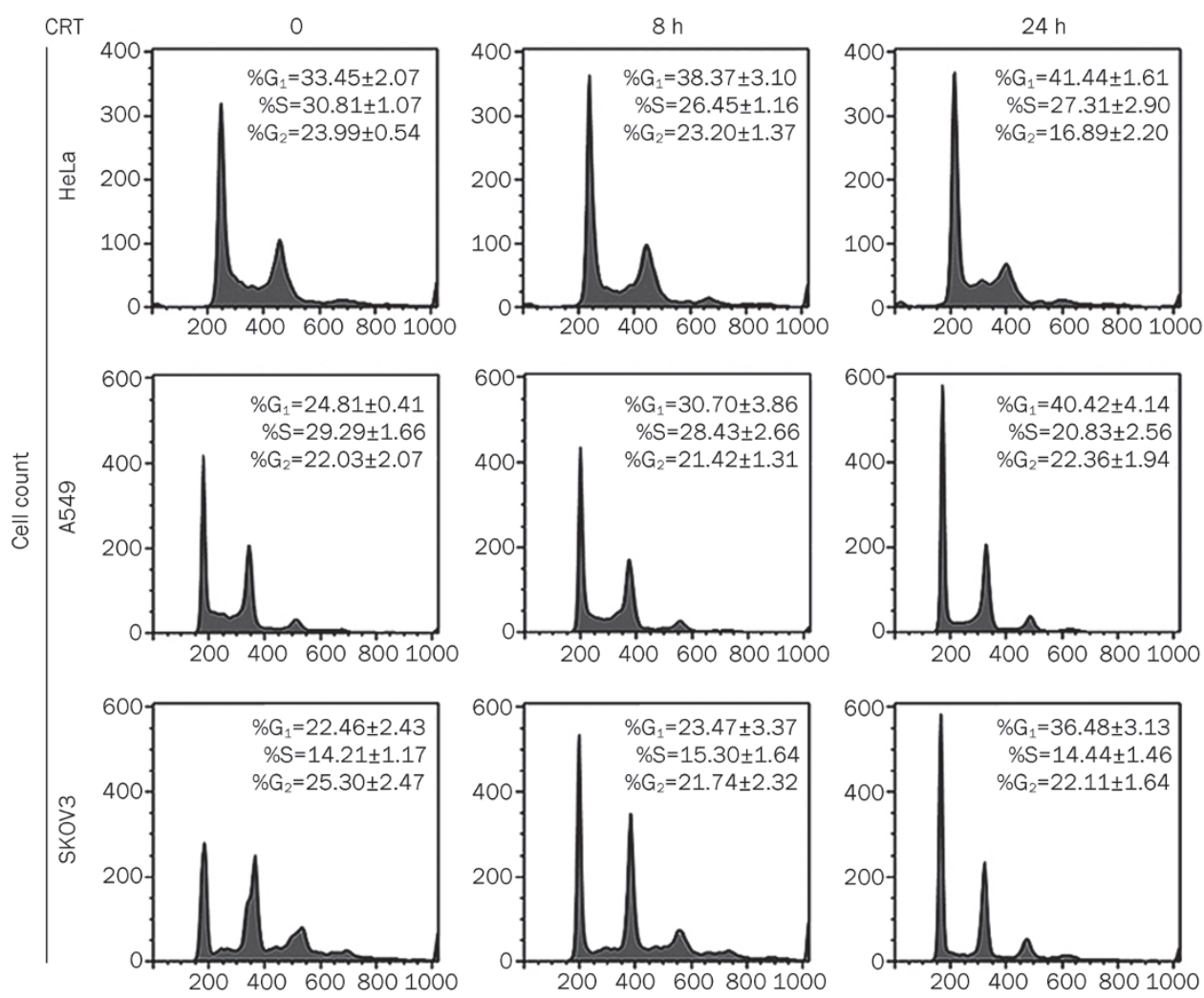

Figure 2. Crocetin induces cell cycle arrest in cancer cells. HeLa, A549, and SKOV3 cells were treated with crocetin $(240 \mu \mathrm{mol} / \mathrm{L})$ for the indicated times. The cells were collected, fixed and stained with PI followed by flow cytometric analysis.

A

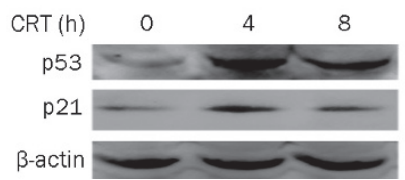

B

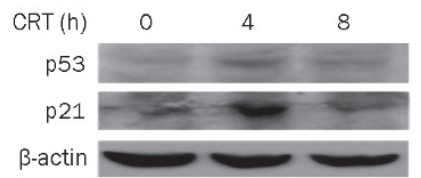

C

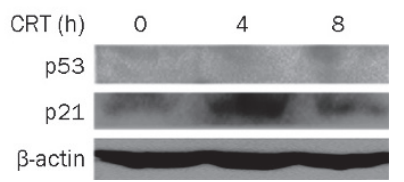

Figure 3. Crocetin induces $p 53$ and $p 21^{\text {WAF } 1 / \text { Cip } 1}$ in cancer cells. HeLa (A), A549 (B), and SKOV3 cells (C) were treated with crocetin (240 $\mu$ mol/L) for the indicated time. Using Western blot analysis, p53 and p21 ${ }^{\text {WAF } 1 / \text { Cip1 }}$ protein expression were evaluated. $\beta$-actin was detected as an input control.

cells were incubated with crocetin for different times as indicated. Floating and attached cells were collected, fixed, and stained with PI. The percentage of cells containing sub-G ${ }_{1}$ DNA content, which is a measure of apoptosis, was detected using flow cytometric analysis. Figure $5 \mathrm{~A}$ shows that crocetin treatment resulted in an increase of sub- $\mathrm{G}_{1}$ phase in a timedependent manner, which was most evident at $72 \mathrm{~h}$ post-treatment. The crocetin-induced apoptosis was further confirmed using flow cytometry after Annexin V-FITC and PI double staining. Early and late apoptotic cells were increased in a dose-dependent manner in crocetin-treated HeLa cells (Figure $5 \mathrm{~B})$. The cell distribution in $\mathrm{Q} 1$ (Annexin $\mathrm{V}^{-} / \mathrm{PI}^{+}$) in samples that were treated with high concentrations of crocetin was slightly increased. These results indicate necrotic and very late apoptotic cell death (Figure 5B) and suggest that the main killing mechanism of crocetin is inducing apoptosis and possibly necrosis. The decrease of pro-caspase 9 , which indicates caspase- 9 activation, was detected at $24 \mathrm{~h}$ post crocetin treatment. Crocetin treatment also markedly triggered caspase-3 activation and PARP cleavage (115 kDa) to generate a 23-kDa fragment, which are hallmarks of apoptosis induction (Figure $5 \mathrm{C})$. These results demonstrate that crocetin treatment activates the caspase cascade to promote apoptosis. Additionally, the pan-caspase inhibitor Z-VAD-FMK effectively suppressed crocetin-induced cytotoxicity in HeLa, A549, and SKOV3 cells (Figure 5D), substantiating that crocetin induced cell death via apoptosis. Collectively, these results suggest that prolonged exposure of crocetin induces cytotoxicity through apoptosis in cancer cells.

\section{Crocetin sensitizes cancer cells to vincristine-induced cytotoxicity} Chemoresistance is a major issue that hinders chemotherapy in the treatment of cancer patients. As a naturally occurring compound, crocetin has been shown to be safe and has low toxicity in vivo ${ }^{[11,18]}$, which indicates a potential role as a chemosensitizing agent. However, the combined effect of crocetin with other conventional chemotherapeutic drugs has never been tested. To address this question, we treated HeLa 

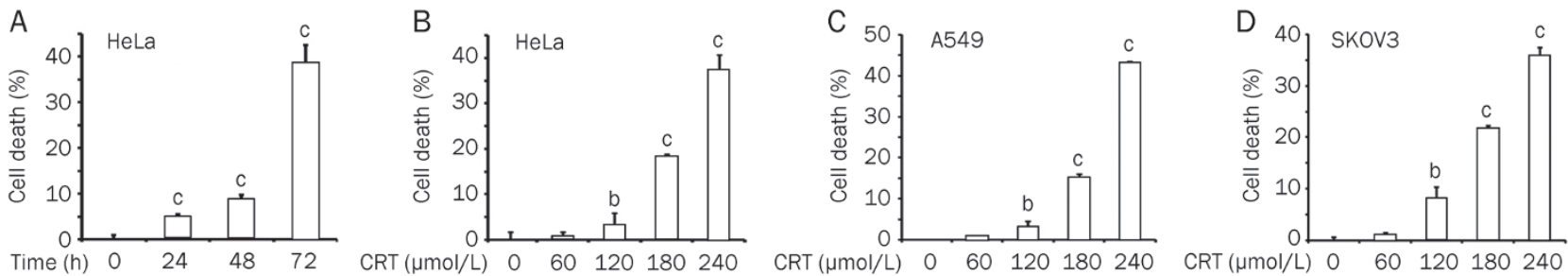

Figure 4. Crocetin induces cytotoxicity in cancer cells in a time-dependent manner. (A) HeLa cells were treated with $240 \mu \mathrm{mol} / \mathrm{L} \mathrm{crocetin}$ for the indicated times. Cell death was detected using the LDH assay. HeLa (B), A549 (C), and SKOV3 cells (D) were treated with different concentrations of crocetin for $72 \mathrm{~h}$. Cell death was detected using LDH release assay. Columns, mean of three independent experiments; bars, SD. ${ }^{b} P<0.05,{ }^{\mathrm{C}} P<0.01 \mathrm{vs}$ control.

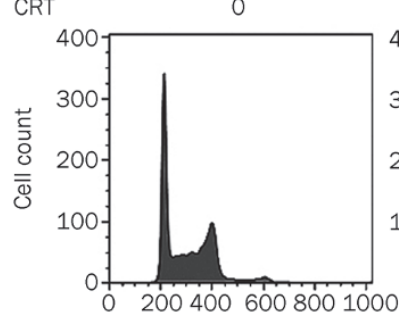

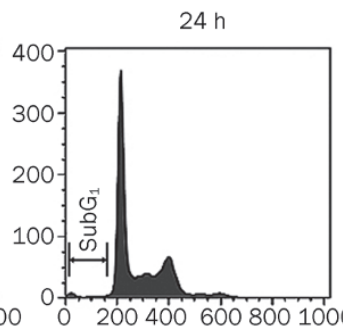
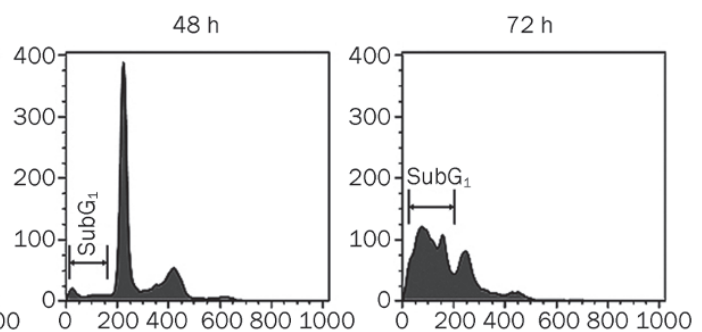

B
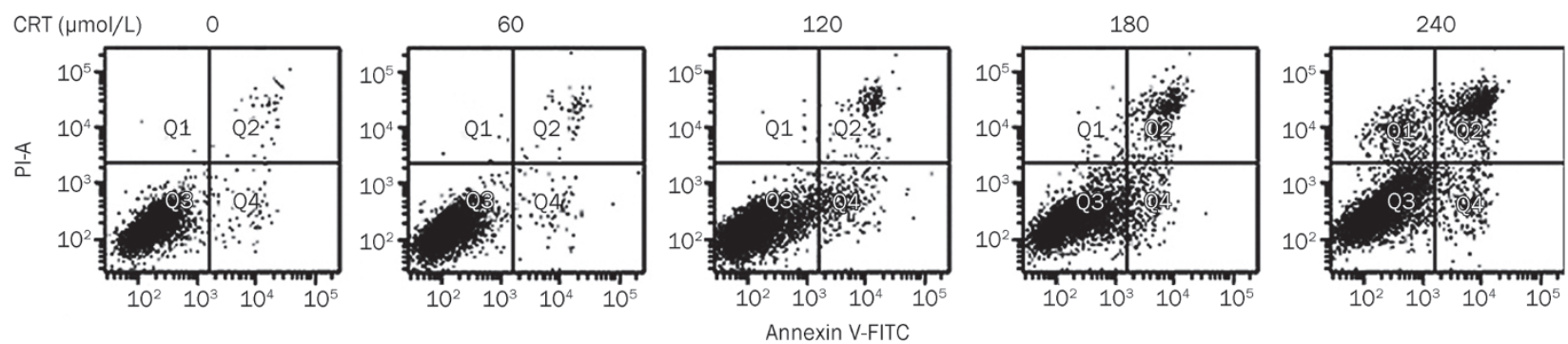

C
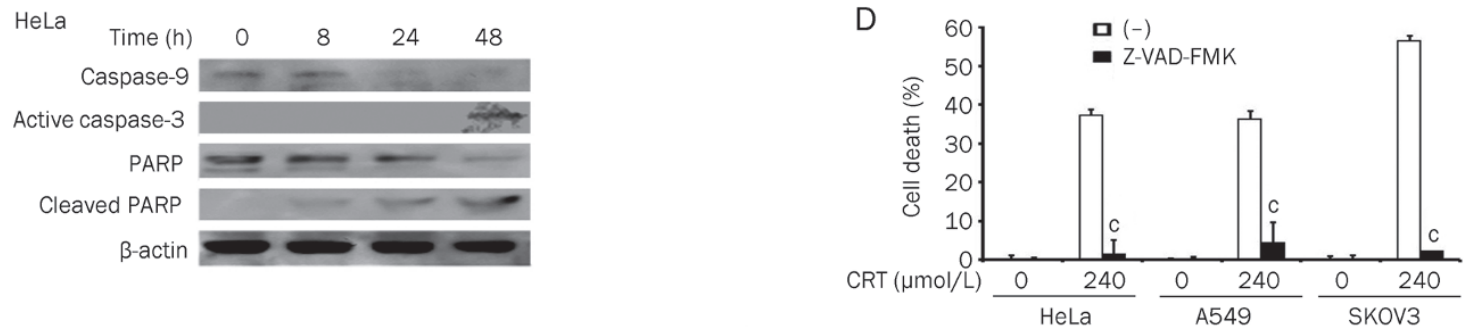

Figure 5. Crocetin induces cytotoxicity by enhancing apoptosis in cancer cells. (A) HeLa cells were treated with crocetin $(240 \mu \mathrm{mol} / \mathrm{L})$ for the indicated time. Floating and attached cells were collected, stained with PI and detected using flow cytometry. (B) HeLa cells were treated with different doses of crocetin for $48 \mathrm{~h}$ and stained with Annexin $\mathrm{V}$ and $\mathrm{Pl}$, followed by flow cytometric analysis. Early apoptosis was defined by Annexin $\mathrm{V}^{+} / \mathrm{Pl}^{-}$staining (Q4), and late apoptosis was defined by Annexin $\mathrm{V}^{+} / \mathrm{PI}^{+}$staining (Q2). (C) HeLa cells were treated with crocetin (240 $\left.\mu \mathrm{mol} / \mathrm{L}\right)$ for the indicated times. Caspase-3, -9, and PARP were detected by Western blot. $\beta$-actin was used as an input control. (D) HeLa, A549, and SKOV3 cells were pretreated with Z-VAD-FMK $(20 \mu \mathrm{mol} / \mathrm{L})$ for $30 \mathrm{~min}$ or left untreated. All cells were treated with crocetin $(240 \mu \mathrm{mol} / \mathrm{L})$ for $72 \mathrm{~h}$. Cell death was measured using the LDH assay. $n=3$. Mean \pm SD. ${ }^{c} P<0.01$ vs crocetin alone.

cells, A549 cells, and SKOV3 cells with the combination of crocetin and different types of conventional chemotherapeutic drugs. No significant sensitization effects were observed when crocetin was used in combination with cisplatin, carboplatin, etopside, adriamycin, pirarubicin, Taxol, docetaxol, dacarbazine, actinomycin $\mathrm{D}$, or fluorouracil (data not shown).
In contrast, simultaneous treatment with crocetin and vincristine synergistically induced cell death (Figure 6A). Notably, the synergistic cytotoxicity was also detected in the vincristine-resistant breast cancer cell line MCF-7/VCR. Although 2 $\mu \mathrm{mol} / \mathrm{L}$ vincristine, which is a concentration that kills most of the parental MCF-7 cells, was nontoxic to MCF-7/VCR cells 

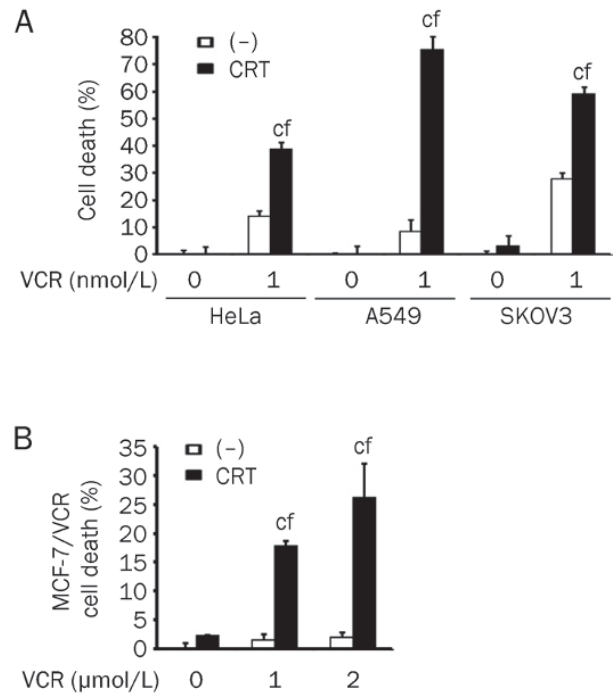

Figure 6. Crocetin sensitizes cancer cells to vincristine-induced cytotoxicity. (A) HeLa, A549, and SKOV3 cells were treated with crocetin (60 $\mu \mathrm{mol} / \mathrm{L})$ or VCR $(1 \mathrm{nmol} / \mathrm{L})$ separately or in combination for $72 \mathrm{~h}$. Cell death was detected using the LDH assay. (B) The vincristine-resistant breast cancer cell line (MCF-7/VCR) was treated with crocetin $(60 \mu \mathrm{mol} / \mathrm{L})$ or VCR $(1 \mu \mathrm{mol} / \mathrm{L}$ or $2 \mu \mathrm{mol} / \mathrm{L})$ separately or in combination for $72 \mathrm{~h}$. Cell death was measured using the LDH assay. $n=3$. Mean \pm SD. ${ }^{c} P<0.01$ vs crocetin alone, ${ }^{f} P<0.01$ vs VCR alone.

(less than $5 \%$ of cell death), vincristine in combination with crocetin showed cytotoxicity in approximately $30 \%$ of MCF-7/ VCR cells (Figure 6B). These results suggest that the combination of crocetin and vincristine would greatly improve the anticancer value of vincristine.

\section{Discussion}

In this study, we demonstrated two distinct anticancer functions of crocetin as follows: to inhibit cell proliferation at early time by inducing cell cycle arrest in different human cancer cell types via p53-dependent and -independent $\mathrm{p} 21^{\mathrm{WAF1} / \mathrm{Cip} 1}$ mediated mechanisms and to kill cancer cells via apoptosis. We demonstrated that crocetin sensitized cancer cells to vincristine-induced cell death. Importantly, crocetin restored vincristine sensitivity in the vincristine-resistant breast cancer cell line MCF-7/VCR. To our knowledge, this is the first report showing the chemosensitizing effect of crocetin on vincristineinduced cytotoxicity in cancer cells. Therefore, our results suggest that crocetin may function as a potential anticancer agent as a chemotherapeutic drug or a chemosensitizer for vincristine.

The molecular mechanism underlying the anticancer property of crocetin remains poorly understood. Crocetin inhibits DNA, RNA, and protein synthesis in malignant cells ${ }^{[14,19]}$. Crocetin may also directly interact with DNA and RNA to induce changes in their conformations. Among the three major carotenoids that are derived from saffron (crocin, crocetin, and dimethylcrocetin), crocetin had the highest binding affinity for $\mathrm{DNA}^{[20-22]}$. A previous study has shown that crocetin sup- presses TPA-induced expression of oncogenes in the mouse epidermis and inhibits TPA-induced skin carcinogenesis ${ }^{[23]}$. Another in vivo study has shown that crocetin displays antitumor activities in a lung cancer animal model by scavenging free radicals ${ }^{[24]}$.

Because p53 is mutated in approximately $50 \%$ of human tumors, we selected three cancer cell lines with different statuses of p53 to study the anticancer effects of crocetin. The results show that crocetin inhibits cell proliferation by inducing $\mathrm{G}_{1}$ arrest. We demonstrated that crocetin induced cell cycle arrest via p53-dependent and -independent pathways in cancer cell lines with wild type p53 (A549) and mutated p53 (SKOV3). Crocetin slightly increased the p53 expression level in HeLa cells, suggesting that crocetin may partly counteract the p53 suppressive function of the HPV oncogene E6. In turn, p53 induces the expression of downstream p21 $21^{\text {WAF1/Cip1 }}$ in HeLa cells to suppress cell proliferation. Further investigation is required to understand how crocetin counteracts the p53-suppressing function of E6. The DNA-damaging agent cisplatin represses virally coded E6 proteins and contributes to the restoration of 553 expression in cisplatin treated HeLa cells ${ }^{[25]}$. It would be interesting to determine whether crocetin functions to activate p53 through DNA damage. Crocetinmediated $\mathrm{p} 21^{\mathrm{WAF} 1 / \mathrm{Cip} 1}$ induction was detected in the p53-null SKOV3 cells, which have rearrangements in the p53 gene that prevent the production of detectable protein products. These results suggest that crocetin activates $\mathrm{p} 21^{\mathrm{WAF} 1 / \mathrm{Cip} 1}$ through a p53-independent mechanism. Consistent with our results, p53-independent induction of $\mathrm{p}^{21^{\mathrm{WAF} 1 / \mathrm{Cip} 1}}$ and concomitant $\mathrm{G}_{1}$ arrest have been previously reported in malignant cells ${ }^{[26,27]}$. The induction of $\mathrm{p} 21^{\mathrm{WAF} 1 / \mathrm{Cip} 1}$ may contribute to $\mathrm{G}_{1}$ arrest in crocetin-treated cancer cells because p21 ${ }^{\mathrm{WAF} 1 / \mathrm{Cip} 1}$ inhibits the activity of cyclin dependent kinases (Cdks) or proliferating cell nuclear antigen (PCNA). Therefore, $\mathrm{p} 21^{\mathrm{WAF} 1 / \mathrm{Cip} 1}$ functions as a suppressor of cell cycle progression at the $\mathrm{G}_{1}$ checkpoint $^{[28,29]}$. The roles of cyclins and Cdks in crocetin-induced cell cycle arrest warrant further study.

The MTT assay, which detects viable cells, does not discriminate cell loss that is caused by cell death from that caused by suppression of proliferation. However, the LDH release assay is widely used to detect cell death resulting from apoptosis. Apoptotic cells under tissue culture conditions will eventually leak their cytoplasmic contents because they do not undergo phagocytosis, which occurs in vivo. Using the LDH assay and flow cytometric analysis, we showed that prolonged incubation of crocetin killed cancer cells via apoptosis, which was associated with the activation of caspase- 9 to initiate the intrinsic apoptosis pathway. Although the exact mechanism for crocetin-induced apoptotic activation requires further investigation, our results demonstrate that induction of apoptosis at least partly contributes to the anticancer activity of crocetin. In addition, crocetin significantly enhanced the anticancer activity of vincristine in cancer cells. The ability of crocetin to restore vincristine sensitivity in the vincristine-resistant cancer cells suggests a potential role as a chemosensitizer for certain anticancer therapeutics such as vincristine. The mechanism 
that mediates vincristine-specific sensitization is currently unknown. A vincristine-specific pathway or molecule may be activated in response to crocetin treatment, which enhances the cell killing mechanism of vincristine.

In our study, the $\mathrm{IC}_{50}$ values of crocetin on cell proliferation were from 100-120 $\mu \mathrm{mol} / \mathrm{L}$, which are comparable with that from a study by Dhar ${ }^{[11]}$. Several animal experiments have shown that high doses of crocetin in vivo are well-tolerated and relatively nontoxic with a potential to exert anticancer activities $^{[11,14,24]}$. These data indicate the possibility that crocetin may be used at relatively high doses for cancer therapy. The solubility and the bioavailability of crocetin require optimization before being used as an effective anticancer drug. It is also intriguing that the suppression of proliferation and cytotoxic effects of crocetin are not dependent on the p53 status in cancer cells. This advantage is highly relevant because p53 is mutated in approximately $50 \%$ of tumors. This study provides novel evidence for the potential use of crocetin as an anticancer agent, which requires further investigation in vivo.

\section{Acknowledgements}

This study was supported in part by grants from the National Natural Science Foundation of China (No 30772539 and 30973403), the Young Scientist Fund of Science \& Technology Department of Sichuan Province in China (2010JQ0012), the Scientific Research Foundation for the Returned Overseas Chinese Scholar at the State Education Ministry of China, the Program for Changjiang Scholars and the Innovative Research Team in University (IRT0935).

\section{Author contribution}

Ying-jia ZHONG performed the research and analyzed data. Fang SHI and Xue-lian ZHENG assisted with cell culture and cell death experiments. Qiong WANG, Lan YANG, Hong SUN, and Fan HE assisted with flow cytometry and Western blot experiments. Lin ZHANG assisted with data analysis. Yong QIN synthesized and provided crocetin. Xia WANG, Yong LIN, and Lin-chuan LIAO designed the research, analyzed data, wrote and revised the manuscript.

\section{References}

1 Ordoudi SA, Befani CD, Nenadis N, Koliakos GG, Tsimidou MZ. Further examination of antiradical properties of Crocus sativus stigmas extract rich in crocins. J Agric Food Chem 2009; 57: 3080-6.

2 Kanakis CD, Tarantilis PA, Pappas C, Bariyanga J, Tajmir-Riahi HA, Polissiou MG. An overview of structural features of DNA and RNA complexes with saffron compounds: Models and antioxidant activity. J Photochem Photobiol 2009; 95: 204-12.

3 Lee IA, Lee JH, Baek NI, Kim DH. Antihyperlipidemic effect of crocin isolated from the fructus of Gardenia jasminoides and its metabolite Crocetin. Biol Pharm Bull 2005; 28: 2106-10.

4 Zheng S, Qian Z, Tang F, Sheng L. Suppression of vascular cell adhesion molecule-1 expression by crocetin contributes to attenuation of atherosclerosis in hypercholesterolemic rabbits. Biochem Pharmacol 2005; 70: 1192-9.

5 He SY, Qian ZY, Wen N, Tang FT, Xu GL, Zhou CH. Influence of Crocetin on experimental atherosclerosis in hyperlipidamic-diet quails. Eur $\mathrm{J}$
Pharmacol 2007; 554: 191-5.

6 Cai J, Yi FF, Bian ZY, et al. Crocetin protects against cardiac hypertrophy by blocking MEK-ERK1/2 signalling pathway. J Cell Mol Med 2009; 13: 909-25.

7 Dhar A, Cherian G, Dhar G, Ray G, Sharma R, Banerjee SK. Molecular basis of protective effect by crocetin on survival and liver tissue damage following hemorrhagic shock. Mol Cell Biochem 2005; 278 : 139-46.

8 Ahmad AS, Ansari MA, Ahmad M, Saleem S, Yousuf S, Hoda MN, et al. Neuroprotection by crocetin in a hemi-parkinsonian rat model. Pharmacology, biochemistry, and behavior 2005; 81: 805-13.

9 Giaccio M. Crocetin from saffron: an active component of an ancient spice. Crit Rev Food Sci Nutr 2004; 44: 155-72.

10 Jagadeeswaran R, Thirunavukkarasu C, Gunasekaran P, Ramamurty N, Sakthisekaran D. In vitro studies on the selective cytotoxic effect of crocetin and quercetin. Fitoterapia 2000; 71: 395-9.

11 Dhar A, Mehta S, Dhar G, Dhar K, Banerjee S, Van Veldhuizen P, et al. Crocetin inhibits pancreatic cancer cell proliferation and tumor progression in a xenograft mouse model. Mol Cancer Ther 2009; 8: 315-23.

12 Chryssanthi DG, Lamari FN, latrou G, Pylara A, Karamanos NK, Cordopatis P. Inhibition of breast cancer cell proliferation by style constituents of different Crocus species. Anticancer Res 2007; 27: 357-62.

13 Wang CJ, Lee MJ, Chang MC, Lin JK. Inhibition of tumor promotion in benzo[a]pyrene-initiated CD-1 mouse skin by crocetin. Carcinogenesis 1995; 16: 187-91.

14 Magesh V, DurgaBhavani K, Senthilnathan P, Rajendran P, Sakthisekaran D. In vivo protective effect of crocetin on benzo(a) pyrene-induced lung cancer in Swiss albino mice. Phytother Res 2009; 23: 533-9.

15 Chen W, Wang X, Bai L, Liang X, Zhuang J, Lin Y. Blockage of NFkappaB by IKKbeta- or RelA-siRNA rather than the NF-kappaB supersuppressor IkappaBalpha mutant potentiates adriamycin--induced cytotoxicity in lung cancer cells. J Cell Biochem 2008; 105: 554-61.

16 Wang X, Ju W, Renouard J, Aden J, Belinsky SA, Lin Y. 17-allylamino17-demethoxygeldanamycin synergistically potentiates tumor necrosis factor-induced lung cancer cell death by blocking the nuclear factorkappaB pathway. Cancer Res 2006; 66: 1089-95.

17 Kastan MB, Canman CE, Leonard CJ. P53, cell cycle control and apoptosis: implications for cancer. Cancer Metastasis Rev 1995; 14: 3-15.

18 Abdullaev Fl. Cancer chemopreventive and tumoricidal properties of saffron (Crocus sativus L). Exp Biol Med (Maywood, NJ 2002; 227: 20-5.

19 Abdullaev FI. Inhibitory effect of crocetin on intracellular nucleic acid and protein synthesis in malignant cells. Toxicol Lett 1994; 70: 24351.

20 Bathaie SZ, Bolhasani A, Hoshyar R, Ranjbar B, Sabouni F, MoosaviMovahedi AA. Interaction of saffron carotenoids as anticancer compounds with ctDNA, Oligo (dG.dC)15, and Oligo (dA.dT)15. DNA Cell Biol 2007; 26: 533-40.

21 Kanakis CD, Tarantilis PA, Tajmir-Riahi HA, Polissiou MG. DNA interaction with saffron's secondary metabolites safranal, crocetin, and dimethylcrocetin. DNA Cell Biol 2007; 26: 63-70.

22 Kanakis CD, Tarantilis PA, Tajmir-Riahi HA, Polissiou MG. Interaction of tRNA with Safranal, Crocetin, and Dimethylcrocetin. J Biomol Struct Dyn 2007; 24: 537-46.

23 Hsu JD, Chou FP, Lee MJ, Chiang HC, Lin YL, Shiow SJ, et al. Suppression of the TPA-induced expression of nuclear-protooncogenes in mouse epidermis by crocetin via antioxidant activity. Anticancer Res 
1999; 19: 4221-7.

24 Magesh V, Singh JP, Selvendiran K, Ekambaram G, Sakthisekaran D. Antitumour activity of crocetin in accordance to tumor incidence, antioxidant status, drug metabolizing enzymes and histopathological studies. Mol Cell Biochem 2006; 287: 127-35.

25 Wesierska-Gadek J, Schloffer D, Kotala V, Horky M. Escape of p53 protein from E6-mediated degradation in HeLa cells after cisplatin therapy. Int J Cancer 2002; 101: 128-36.

26 Lee SJ, Ha MJ, Lee J, Nguyen P, Choi YH, Pirnia F, et al. Inhibition of the 3-hydroxy-3-methylglutaryl-coenzyme A reductase pathway induces $p 53-i n d e p e n d e n t$ transcriptional regulation of $\mathrm{p} 21^{\text {WAF1/CIP1 }}$ in human prostate carcinoma cells. J Biol Chem 1998; 273: 10618-23.

27 Nakano K, Mizuno T, Sowa Y, Orita T, Yoshino T, Okuyama Y, et al. Butyrate activates the WAF1/Cip1 gene promoter through Sp1 sites in a p53-negative human colon cancer cell line. J Biol Chem 1997; 272 : 22199-206.

28 Aikawa T, Segre GV, Lee K. Fibroblast growth factor inhibits chondrocytic growth through induction of p21 and subsequent inactivation of cyclin E-Cdk2. J Biol Chem 2001; 276: 29347-52.

29 Kelman Z. PCNA: structure, functions and interactions. Oncogene 1997; 14: 629-40. 